\title{
HORMONE (ACTH, T3) CONTENT OF IMMUNOPHENOTYPED LYMPHOCYTE SUBPOPULATIONS
}

\author{
Éva PÁllinger, Gergely Attila Kiss and György CsabA* \\ Department of Genetics, Cell- and Immunobiology, Semmelweis University, \\ Budapest, Hungary
}

(Received: 14 May 2016; accepted: 29 August 2016)

\begin{abstract}
Cells of the immune system synthesize, store, and secrete polypeptide and amino acid type hormones, which also influence their functions, having receptors for different hormones. In the present experiment immunophenotyped immune cells isolated from bone marrow, thymus, and peritoneal fluid of mice were used for demonstrating the adrenocorticotropic hormone (ACTH) and triiodothyronine (T3) hormone production of differentiating immune cells. Both hormones were found in each cell type, and in each maturation state, which means that all cells are participating in the hormonal function of the immune system. The lineage-independent presence of $\mathrm{ACTH}$ and $\mathrm{T} 3$ in differentiating hematopoietic cells denotes that their expression ubiquitous during lymphocyte development. Higher ACTH and T3 content of B cells shows that these cells are the most hormonally active and suggests that the hormones may have an autocrine regulatory role in B cell development. Developing $\mathrm{T}$ cells showed heterogeneous hormone production which was associated with their maturation state. Differences in the hormone contents of immune cells isolated from different organs indicate that their hormone production is defined by their differentiation or maturation state, however, possibly also by the local microenvironment.
\end{abstract}

Keywords: hormones, developing lymphocytes, lymphocyte subpopulations, immunophenotype

\section{Introduction}

Bidirectional communication between the immune system and the endocrine system, mainly the hypothalamic-pituitary-adrenal (HPA) axis, is well known $[1,2]$. Proinflammatory cytokines (TNF $\alpha$, IL-1, and IL-6) produced by innate immune cells and also activated $\mathrm{T}$ cell-derived cytokines (IL-2 and INF- $\gamma$ ) stimulate glucocorticoid release from adrenal gland [3, 4]. On the other hand,

*Corresponding author; E-mail: csaba.gyorgy@med.semmelweis-univ.hu 
glucocorticoids reduce the synthesis and/or release of proinflammatory cytokines by negative feedback, and also regulate Th1/Th2 balance (shift to Th2 response) $[5,6]$. Immune cells can be characterized by exofacial and intracellular hormone receptor pattern, which make them sensitive to many hormones [7]. It is also proved that immune cells are able to synthesize hormones, as endocrine glands can produce cytokines [8-11]. Immune cell-derived hormones may be endogenous regulators of cell functions and may also transfer information from the immune system to the neuroendocrine system $[11,12]$. The presence of intracellular LHlike factor [13], growth hormone releasing hormone [14], thyrotropic hormone and triiodothyronine (T3) [15], adrenocorticotropic hormone (ACTH) [16], endorphin $[17,18]$, human chorionic gonadotropin (HCG) [19], calcitonin [20], and insulin [21] could be detected both in animal and human immune cells [22-24]. Likewise, the presence of biogenic amines (histamine, serotonin, and epinephrine) was also demonstrated $[23,25]$.

However, several data verified the presence of hormones in lymphocytes, and also characterized their immune regulatory effects; there is no any data about the connection of the hormone content of immune cells and their differentiation states. The aim of our study was to compare the ACTH and T3 hormone contents of B lymphocyte subpopulations and in developing $\mathrm{T}$ cell subsets.

\section{Materials and Methods}

\section{Animals}

Six weeks old male BALB/c mice were used for the experiments. The animals were maintained under standard conditions. All experimental groups contained 6 mice $(n=6)$. Mice were sacrificed by ether narcosis on the day of the measurements. Peritoneal cells were collected by washing out the peritoneal cavity with sterile filtered phosphate buffered saline (PBS) solution. After dissecting the femora, bone marrow cells were washed out of the bone marrow cavity with a stream of sterile filtered PBS solution. Thymocytes were isolated mechanically and filtered through a 30- $\mu \mathrm{m}$ Filcon filters (BD Biosciences, San Jose, CA, USA).

\section{Sample preparation for flow cytometric analysis}

Mature and immature lymphocyte subpopulations were determined by multicolor flow cytometry. Antibodies used for immunophenotyping were manufactured by BD Biosciences Pharmingen (San Jose, CA, USA) or Sony 
Biotechnology Inc. (Tokyo, Japan). The "Direct Immunofluorescence Staining of Cells Using a Lyse/No-Wash Procedure" protocol of BD Biosciences [26] was used for staining the cell surface antigens. Lysed and washed cells were fixed by 4\% paraformaldehyde (Sigma-Aldrich Ltd., St. Louis, MO, USA) and permeabilized by $0.1 \%$ saponin solution (Sigma-Aldrich Ltd., St. Louis, MO, USA) for labeling of intracellular hormones (ACTH and T3). Antibodies against ACTH and T3 hormones were purchased from Sigma-Aldrich Company (St. Louis, MO, USA). The staining specificity was performed by using isotype control antibodies.

Immunophenotyping analysis of lymphocytes was completed by using four color marker combinations as indicated in Table I.

Identification of bone marrow cells. Hematopietic stem cells (HSC) were defined by the high expression level of exofacial Scal antigen (Stem cells antigen-1 $=$ glycosylphosphatidylinositol-anchored cell surface protein=GPI-AP) and the absence of IL7R $\alpha$ (interleukin-7 receptor alpha chain) (Scalhigh+/IL7Ra-). Common lymphoid progenitor (CLP) cells were identified by the surface expression of IL7R $\alpha$ and the lower expression level of Scal (Scallow+/IL7Ra+). Mature B lymphocytes were characterized by the cell surface expression of B220 antigen (CD45R), while T cells were described by CD3 (T-cell co-receptor) expression.

Identification of thymocyte subsets [27]. CD44 (cell-surface glycoprotein encoded by the CD44 gene on chromosome 11), CD25 (alpha chain of the IL2 receptor), CD3 (T-cell co-receptor), CD4 (member of the immunoglobulin superfamily encoded by the CD4 gene), and CD8 (co-receptor for the T cell receptor) antibodies were used for the characterization of the maturation states of

Table I. Immunophenotyping analysis of lymphocyte subpopulations

\begin{tabular}{lcccc}
\hline & \multicolumn{3}{c}{ Fluorochromes - Antibodies } \\
\cline { 2 - 5 } Sample & FITC (Alexa488) & Pe & PerCP-Cy5.5 & APC \\
\hline Bone marrow & ACTH & Sca1 & IL7Ra & \\
Bone marrow & T3 & Sca1 & IL7Ra & \\
Bone marrow & ACTH & B220 & IL7Ra & CD3 \\
Bone marrow & T3 & B220 & IL7Ra & CD3 \\
Thymus & CD44 & ACTH & & CD25 \\
Thymus & CD44 & T3 & & CD25 \\
Thymus & CD44 & ACTH & & CD25 \\
Thymus & CD44 & T3 & & CD25 \\
Thymus & CD8 & ACTH & CD4 & CD3 \\
Thymus & CD8 & T3 & CD4 & CD3 \\
Thymus & CD8 & ACTH & CD4 & CD3 \\
Thymus & CD8 & T3 & CD4 & CD19 \\
Peritoneal fluid & ACTH & CD5 & & CD19 \\
Peritoneal fluid & T3 & CD5 & & \\
\hline
\end{tabular}


thymocytes. Double negative (DN) thymocytes were identified by the cell surface expression of CD44 and CD25. DN1 cells were verified by the CD44+/CD25immunophenotype, DN2 cells by the co-expression of CD44 and CD25 (CD44+/ CD25+). DN4 thymocytes were characterized by the exofacial CD8 positivity without the surface expressions of CD4 and CD3 (CD8+/CD4-/CD3-). Two subsets of double positive (DP) cells were separated on the basis of cell surface expression of CD3 $\mathrm{T}$ cell co-receptor, the CD3 negative (CD4+/CD8+/CD3-) and the $\mathrm{CD} 3$ positive $(\mathrm{CD} 4+/ \mathrm{CD} 8+/ \mathrm{CD} 3+)$ subsets. Single positive (SP) thymocytes were determined by the presence or the absence of CD4 and CD8 molecules (SP CD4+ = CD4+/CD8-/CD3 + and SP CD8+ = CD4-/CD8+/CD3 + )

Identification of B lymphocytes in peritoneal fluid. B lymphocyte subsets were specified on the basis of cell surface expression of CD5 (Lymphocyte Antigen T1/ Leu-1). B1 B cells were classified by the CD19+/CD5 DP immunophenotyped, while B2 B lymphocytes were described by the CD19+/CD5- marker combination.

\section{FACS measurements}

Measurements were carried out using a FACSCalibur flow cytometer (Becton Dickinson, San Jose, CA, USA) on the day of the staining, collecting $2.5 \times 10^{4}$ to $1 \times 10^{5}$ cells/tube. CellQuest-Pro software (Becton Dickinson, San Jose, CA, USA) was used for acquisition and analysis. The lymphocyte population (lymphocyte gate) was defined on the basis of their size and granularity (FS/SS dot plot). The relative expression levels of intracellular hormones were analyzed by the comparison of geometric mean channel values of fluorescence (mean fluorescence intensity, MFI).

\section{Statistical analysis}

Excel 7.0 software was used for data processing. Statistical differences between the studied groups were tested using "GraphPad Prism 6" (San Diego, CA, USA) software. Statistical significance was defined as $p<0.05$.

\section{Results and Discussion}

Both ACTH and T3 could be detected in each investigated lymphocyte subpopulation (B and $\mathrm{T}$ lymphocytes and their precursors) separated from the bone marrow, the thymus, or the peritoneal fluid. It means that the presence (synthesis, storage, and secretion) of these hormones is lineage-independent. On 
the other hand, the presence of ACTH and T3 in the early maturation states of lymphocytes also denotes that their expression ubiquitous during lymphocyte development. However, the relative expression levels of both ACTH and T3 differed in the investigated lymphocytes subpopulations.

\section{Hormone content of bone marrow lymphocytes}

Although both ACTH and T3 could be detected in each cells separated from bone marrow, the expression levels of the hormones showed differences. B220+ B lymphocytes express significantly higher amounts of ACTH (mean \pm SE: $76.3 \pm$ 2.83 ) than T3 (mean \pm SE: $34.29 \pm 1.29)$ hormone $(p<0.0001)$. Opposite of it, the $\mathrm{CD} 3+\mathrm{T}$ cells contained significantly higher amounts of $\mathrm{T} 3$ hormone (mean $\pm \mathrm{SE}$ : $42.77 \pm 2.84)$ compared to ACTH level (mean \pm SE: $29.99 \pm 1.03)(p=0.001)$. There was no significant difference between the expression levels of ACTH and T3 in early hematopoietic progenitors, neither in HSC nor in CLP cell types. The relative expression levels of ACTH were higher in each investigated cell population compared to the $\mathrm{T} 3$ content, except in the case of $\mathrm{T}$ lymphocytes.

Mature B lymphocytes express significantly higher amounts of ACTH than the other investigated cells (Figure 1).

Our results are in line with in vitro experiments of Bost et al. [28] and Johnson et al. [29] and suggest that ACTH may have an autocrine regulatory role in B cell development in vivo too. It would also be possible that the in vitro

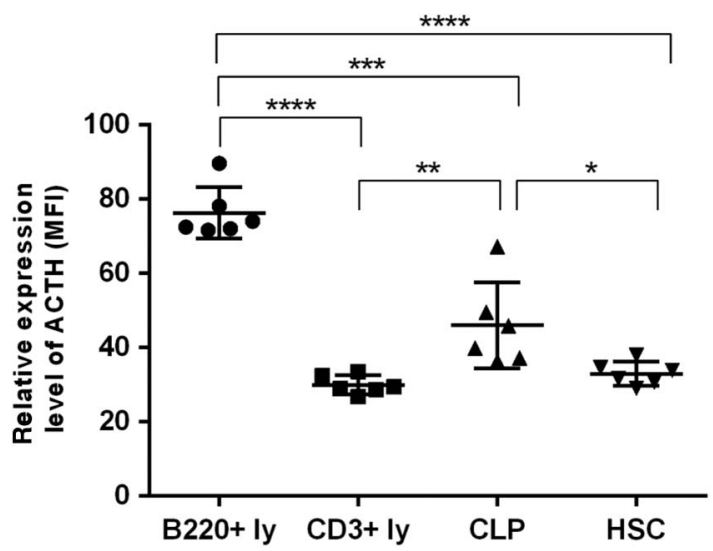

Figure 1. ACTH content of bone marrow-derived cells. Mean fluorescence intensity (MFI) of ACTH expression of bone marrow-derived immunophenotyped leukocytes. Symbols represent individual animals and horizontal bars represent means. ${ }^{*} p<0.05 ; * * p<0.01 ; * * p<0.001$;

$$
* * * * p<0.0001 \text { (unpaired } t \text {-test) }
$$




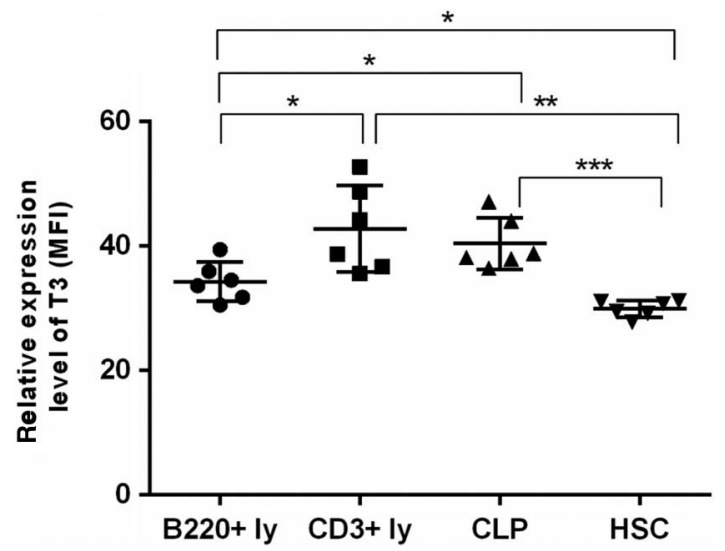

Figure 2. T3 content of bone marrow-derived cells. MFI of T3 expression of bone marrow-derived immunophenotyped leukocytes. Symbols represent individual animals and horizontal bars represent means. ${ }^{*} p<0.05 ; * * p<0.01 ; * * * p<0.001$ (unpaired $t$-test)

determined effects of ACTH on the growth and differentiation of mature B lymphocytes are also important factors in bone marrow B cell development. On the other hand, ACTH produced by bone marrow cells may have a regulatory role in hematopoiesis.

Significant differences could be detected between the T3 hormone content of investigated bone marrow cells as well. Significantly lower expression level of T3 was in the earliest hematopoietic differentiation state in HSC population (mean \pm SE: $29.91 \pm 0.54)$ compared to all other cell types (mean \pm SE: B220+ ly $=34.29 \pm$ 1.29; CD3+ ly =42.77 $\pm 2.84 ; \mathrm{CLP}=40.41 \pm 1.70$ ) (Figure 2).

Several data prove the presence of thyroid hormone receptors in progenitor cells and also the regulatory effects of thyroid hormones in developmental and homeostatic process [30-32]. It is also verified that the thyroid hormone receptor expression of HSC depends on the serum levels of thyroid hormones in humans [33]. We determined the presence of T3 hormone in developing and mature bone marrow-derived leukocytes. Our results indicate that the local production of T3 hormone may also regulate the receptor expression of neighboring cells, so the in situ secreted T3 may control the actual hematopoietic activity of bone marrow.

\section{Hormone content of thymocytes}

The presence of both ACTH and T3 could be detected in each investigated thymocyte. Thymocytes express significantly higher amounts of T3 in every maturation states compared to their ACTH content $(p<0.001)$. On the other hand, 
Table II. Relative T3 hormone content of thymocytes (MFI)

\begin{tabular}{lccccccc}
\hline & DN1 & DN2 & DN4 & DP CD3- & DP CD3+ & SP CD4+ & SP CD8+ \\
\hline Mean & 18.27 & 19.6 & 22.48 & 19.43 & 21.32 & 25.5 & 22.22 \\
Std. error of mean & 1.308 & 1.583 & 1.85 & 1.785 & 2.729 & 3.212 & 2.167 \\
\hline
\end{tabular}

the maturation state of thymocytes did not influence of the intracellular T3 content of cells (Table II).

The ACTH content of developing $\mathrm{T}$ cells showed heterogeneity. The T3 concentrations of DN1 stage cells (mean \pm SE: $10.19 \pm 0.16$ ) and CD4+ SP cells (mean \pm SE: $9.54 \pm 0.26$ ) were the lowest. The hormone content of DN1 and CD4+ SP cells was significantly depressed compared to the CD4+/CD8+ DP cells, both in their CD3 negative and in $\mathrm{CD} 3$ positive subsets (Figure 3).

Several data demonstrated the complex connection between glucocorticoids and $\mathrm{T}$ cell development. It is evident that developing thymocytes, particularly the CD4+CD8+ DP cells, are very sensitive to glucocorticoids [34]. It is also well known that the adrenal glucocorticoid synthesis is controlled via a feedback mechanism [35]. The serum glucocorticoid level determines both the corticotropin-releasing factor production of hypothalamus and the pituitary synthesis and secretion of ACTH (HPA axis). It is easy to imagine that glucocorticoids produced in the thymus may also get involved in this highly sensitive regulatory system, as intrathymic glucocorticoid synthesis is monitored by serum ACTH level [36, 37]. The question arises that what is the consequence of the ACTH production of thymocytes?

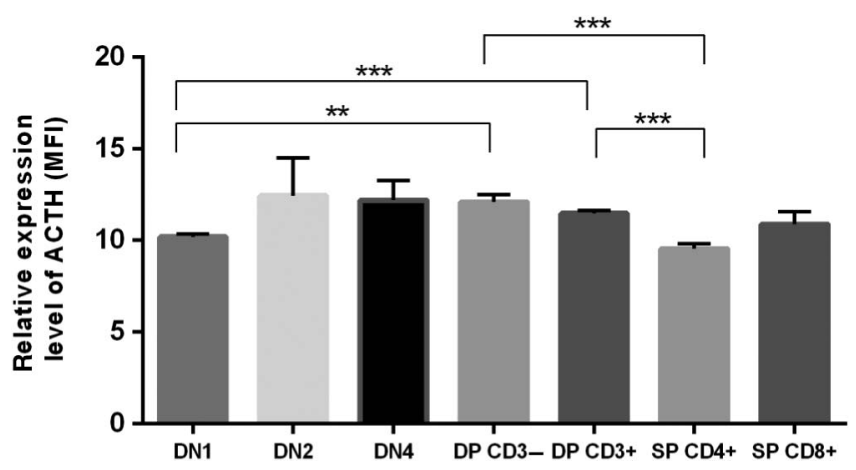

Figure 3. ACTH content of thymus-derived developing T lymphocytes. MFI of ACTH expression (mean $\pm \mathrm{SE}$ ) of developing $\mathrm{T}$ lymphocytes separated from thymus. ${ }^{*} p<0.01 ;{ }^{*} * * p<0.001$ (unpaired $t$-test) 
Hormone content of peritoneal B lymphocytes

B cell subpopulations examined in our study are well characterized [38]. CD19+/CD5- B cells (B2 B lymphocytes) and CD19+/CD5+ DP B cells (B1 B lymphocytes) have different biological functions. Till $\mathrm{B} 1$ cells are involved in $\mathrm{T}$-cell independent antibody response, until then $\mathrm{B} 2$ cells respond to $\mathrm{T}$ cell dependent antigens [39]. It is also known that exofacial CD5 modulate B cell function [40, 41]. The presence of both ACTH and T3 could be detected in B1 (CD19+/CD5+) and B2 (CD19+/CD5-) lymphocytes isolated from the peritoneal fluid. Both B lymphocyte subpopulations expressed significantly higher amounts of ACTH compared to their T3 content $(p<0.001)$. The hormone

(a)

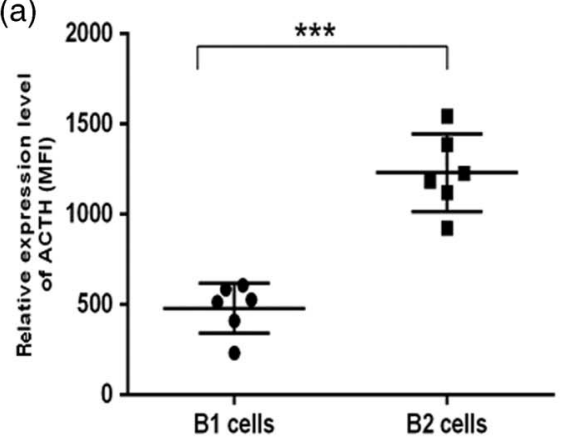

(b)

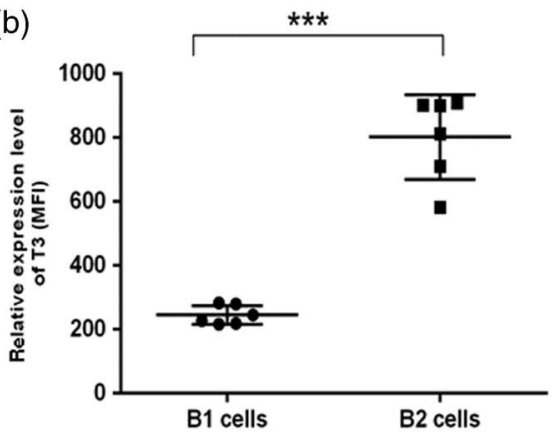

(c)

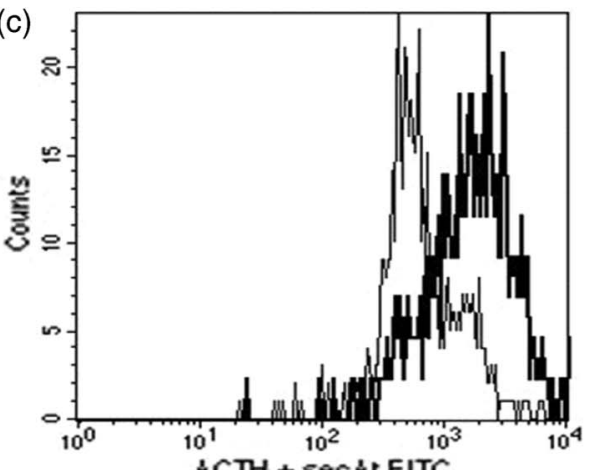

(d)

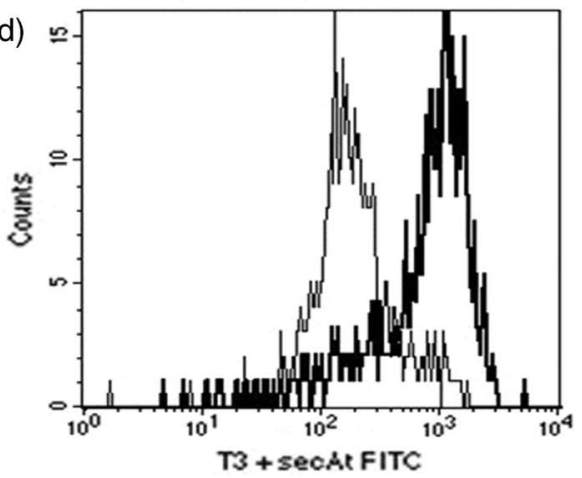

Figure 4. ACTH and T3 contents of peritoneal fluid - derived B lymphocyte subpopulations. MFI of ACTH (a) and T3 (b) expression of B lymphocyte subsets separated from peritoneal fluid. Symbols represent individual animals and horizontal bars represent means. Representative overlay histograms

show the ACTH (c) or T3 (d) content of cell. B1 cells are represented by thin lines and

B2 subpopulation is demonstrated by thick lines on both overlay histograms. $* * * p<0.001$

(unpaired $t$-test) 
contents of B2 lymphocytes were significantly higher compared to the B1 cells $(p<0.0001)$. Our results indicate that ACTH and T3 hormone contents of B lymphocytes are cell subtype dependent (Figure 4).

\section{Comparison of ACTH and T3 hormone content of B lymphocyte subpopulations}

We compared the ACTH and T3 content of B lymphocytes subpopulations separated from bone marrow or peritoneal fluid. Significantly lower amounts of ACTH and T3 could be detected in bone marrow B cells $(p<0.0001)$. Our results indicate that hormone production of immune cells is defined first of all by their differentiation or maturation state (Figure 5).

Comparison of ACTH and T3 hormone content of $T$ lymphocyte subpopulations

We compared the ACTH and T3 content of developing T lymphocytes subpopulations separated from bone marrow or thymus. Significantly higher amounts of ACTH and T3 hormone contents could be detected in the earliest hematopoietic progenitor cells (CLP) compared to the thymus derived cells, both $\mathrm{DN} 1$ population and the $\mathrm{CD} 3$ negative or $\mathrm{CD} 3$ positive DP cells $(p<0.0001)$. The $\mathrm{ACTH}$ and $\mathrm{T} 3$ contents of mature $\mathrm{CD} 3+\mathrm{T}$ cells (isolated from bone marrow) increased, and closed the hormone levels of CLP population. Our results indicate that hormone production of $\mathrm{T}$ lymphocytes is determined by their maturation state (Figure 6).

(a)

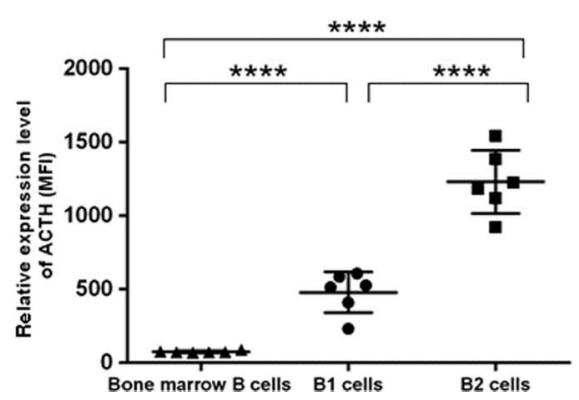

(b)

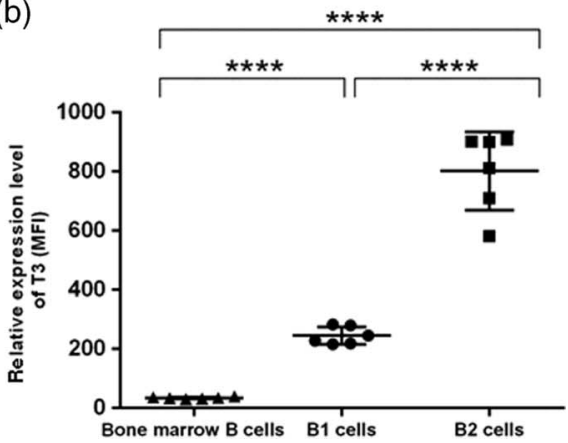

Figure 5. ACTH and T3 contents of B lymphocyte subpopulations separated from bone marrow and peritoneal fluid. MFI of ACTH (a) and T3 (b) expression of B lymphocyte subsets separated from peritoneal fluid (B1 and B2 cells) or from bone marrow. Symbols represent individual animals and horizontal bars represent means. ${ }^{* * * *} p<0.0001$ (unpaired $t$-test) 


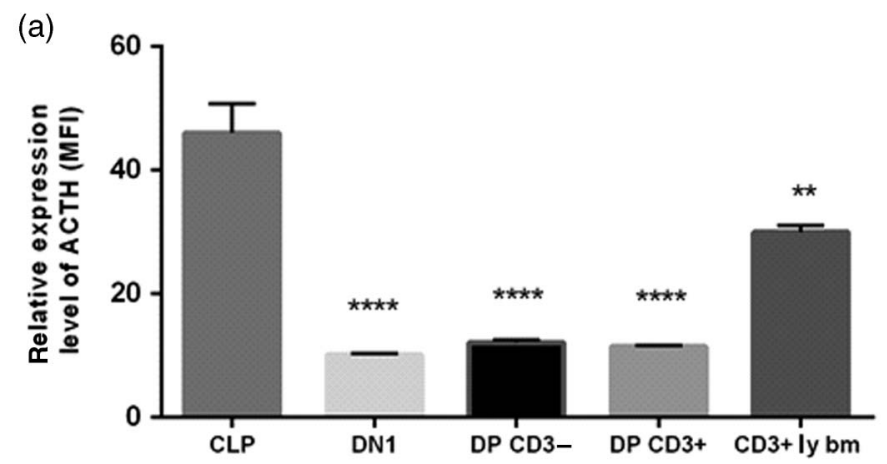

(b)

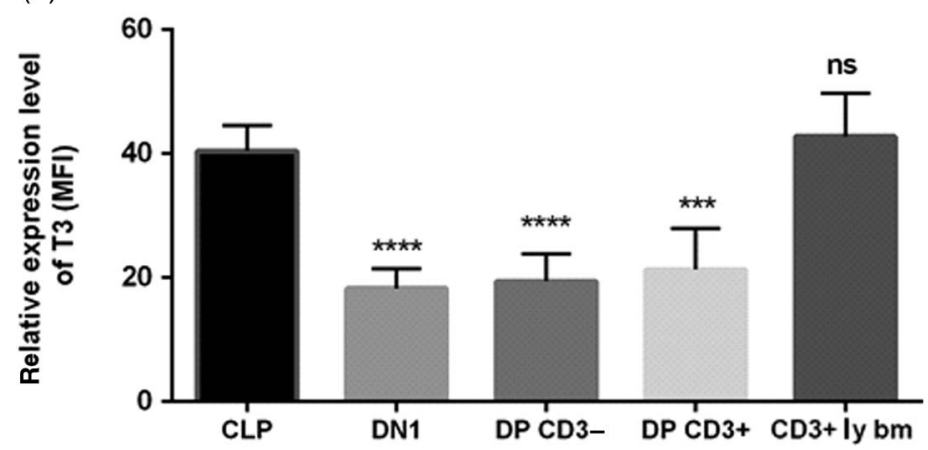

Figure 6. ACTH and T3 hormone content of developing $\mathrm{T}$ lymphocyte subpopulations separated from bone marrow or thymus. MFI of ACTH (a) and T3 (b) expression (mean \pm SE) of developing T lymphocytes separated from bone marrow or thymus. ** $p<0.01$; *** $p<0.001 ; * * * * p<0.0001$ (unpaired $t$-test)

Considering the results, it is clear that each member of the immune system can participate in the endocrine function of the immune cells. However, there are cells, which have an outstanding role, and these cells are B lymphocytes: mature (peritoneal) B lymphocytes and bone marrow B lymphocytes, alike. It can be supposed that the development of endocrine function run parallel with the immunological maturation, as among the three niches of immune cells studied, the most matured and most hormone-loaded lymphatic cells are present in the peritoneal fluid. At the same time, the weakest marker dependent difference is in the various forms of thymocytes. However, in this experiment only two hormones were studied and the situation in case of other hormones (e.g., in the case of amino acid type hormones having membrane receptors) is not known. Further experiments are needed for clearing these problems. Nevertheless, the results of the present experiments call attention again to the earlier not well known hormonal function of immune cells and point to the prominent role of B cells. In addition, the 
results call attention to the universality of hormones in the cells of the mammalian immune system: mice is the third species in which immune cell hormones have been systematically demonstrated.

In the present experiments, the study of hormone secretion was not done because of technical problems; however, this has been already presented by other experiments $[3,12-14,18,19]$.

\section{Acknowledgement}

The authors would like to thank Nóra Fekete for the valuable technical work.

\section{Conflict of Interest}

The authors declare no competing financial interest.

\section{References}

1. Paavonen, T.: Hormonal regulation of immune responses. Ann Med 26, 255-258 (1994).

2. Petrovsky, N.: Towards a unified model of neuroendocrine-immune interaction. Immunol Cell Biol 79, 350-357 (2001).

3. Besedovsky, H. O., del Rey, A., Sorkin, E.: Lymphokine-containing supernatants from con A-stimulated cells increase corticosterone blood levels. J Immunol 126, 385-387 (1981).

4. Besedovsky, H. O., del Rey, A., Sorkin, E., Da Prada, M., Keller, H. H.: Immunoregulation mediated by the sympathetic nervous system. Cell Immunol 48, 346-355 (1979).

5. Späth-Schwalbe, E., Born, J., Schrezenmeier, H., Bornstein, S. R., Stromeyer, P., Drechsler, S., Fehm, H. L., Porzsolt, F.: Interleukin-6 stimulates the hypothalamus-pituitaryadrenocortical axis in man. J Clin Endocrinol Metab 79, 1212-1214 (1994).

6. Smoak, K. A., Cidlowski, J. A.: Mechanisms of glucocorticoid receptor signaling during inflammation. Mech Ageing Dev 125, 697-706 (2004).

7. Kiess, W., Belohradsky, B. H.: Endocrine regulation of the immune system. Klin Wochenschr 64, 1-7 (1986).

8. Csaba, G.: The immuno-endocrine system: Hormones receptors and endocrine function of immune cells. The packed transport theory. Adv Neuroimmune Biol 1, 71-85 (2011).

9. Csaba, G.: Hormonal imprinting in the immune system. Acta Microbiol Immunol Hung 61, 89-106 (2014).

10. Blalock, J. E.: The syntax of the immune-neuroendocrine communication. Immunol Today 15, 504-511 (1994).

11. Weigent, D. A., Blalock, J. E.: Associations between the neuroendocrine and immune system. J Leukoc Biol 58, 137-150 (1995). 
12. Csaba, G.: Hormones in the immune system and their possible role. A critical review. Acta Microbiol Immunol Hung 61, 241-260 (2014).

13. Standaert, F. E., Chew, B. P., Wong, T. S., Michal, J. J.: Porcine lymphocytes secrete a bioactive and immunoactive LH-like factor in response to LHRH and concanavalin A. Am J Reprod Immunol 25, 175-180 (1991).

14. Stephanou, A., Knight, R. A., Lightman, S. L.: Production of a growth hormone-releasing hormone-like peptide and its mRNA by human lymphocytes. Neuroendocrinology $53,628-$ 633 (1991).

15. Csaba, G., Pállinger, É.: Thyrotropic hormone (TSH) regulation of triiodothyronine (T3) concentration in immune cells. Inflamm Res 58, 151-154 (2009).

16. Csaba, G., Pállinger, É.: In vitro effect of hormones on the hormone content of rat peritoneal and thymic cells. Is there an endocrine network inside the immune system? Inflamm Res 56, 447-451 (2007).

17. Csaba, G., Kovács, P., Pállinger, É.: Changes in the endorphin and serotonin content of rat immune cells during adulthood following maternal exposure to ethanol during pregnancy and lactation. Alcohol 38, 111-116 (2006).

18. Cabot, P. J., Carter, L., Gaiddon, C., Zhang, Q., Schafer, M., Loeffler, J. P., Stein, C.: Immune cell-derived beta-endorphin. Production, release, and control of inflammatory pain in rats. J Clin Invest 100, 142-108 (1997).

19. Alexander, H., Zimmermann, G., Lehmann, M., Pfeiffer, R., Schöne, E., Leiblein, S., Ziegert, M.: HCG secretion by peripheral mononuclear cells during pregnancy. Domest Anim Endocrinol 15, 377-387 (1998).

20. Oberhoffer, M., Vogelsang, H., Jager, L., Reinhart, K.: Katacalcin and calcitonin immunoreactivity in different types of leukocytes indicate intracellular procalcitonin content. J Crit Care 14, 29-33 (1999).

21. Pállinger, É., Kovács, G., Horváth, Z., Müller, J., Csaba, G.: Changes in the hormone (ACTH, insulin, epinephrine) content of immune cells in children having acute lymphocytic leukemia (ALL). Acta Microbiol Immunol Hung 60, 423-431 (2014).

22. Pállinger, É., Csaba, G.: Presence and distribution of biogenic amines (histamine, serotonin and epinephrine) in immunophenotyped human immune cells. Inflamm Res 57, 530-534 (2008).

23. Pállinger, É., Csaba, G.: A hormone map of human immune cells showing the presence of adrenocorticotropic hormone, triiodothyronine and endorphin in immunophenotyped white blood cells. Immunology 123, 584-589 (2008).

24. Pállinger, É., Kovács, G., Horváth, Z., Müller, J., Csaba, G.: Changes in the hormone (ACTH, insulin, epinephrine) content of immune cells in children having acute lymphocytic leukemia (ALL). Acta Microbiol Immunol Hung 60, 423-431 (2014).

25. Csaba, G., Pállinger, É.: Is there a possibility of intrasystem regulation by hormones produced by the immune cells? Experiments with extremely low concentrations of histamine. Acta Physiol Hung 96, 369-374 (2009).

26. http://www.bdbiosciences.com/pharmingen/protocols

27. Weerkamp, F., Pike-Overzet, K., Staal, F. J.: T-sing progenitors to commit. Trends Immunol 27, 125-131. (2006).

28. Bost, K. L., Smith, E. M., Wear, L. B., Blalock, J. E.: Presence of ACTH and its receptor on a B lymphocytic cell line: A possible autocrine function for a neuroendocrine hormone. J Biol Regul Homeost Agents 1, 23-27 (1987). 
29. Johnson, E. W., Blalock, J. E., Smith, E. M.: ACTH receptor-mediated induction of leukocyte cyclic AMP. Biochem Biophys Res Commun 157, 1205-1211 (1988).

30. Sirakov, M., Skah, S., Nadjar, J., Plateroti, M.: Thyroid hormone's action on progenitor/ stem cell biology: New challenge for a classic hormone? Biochim Biophys Acta 1830, 3917-3927 (2013).

31. Pascual, A., Aranda, A.: Thyroid hormone receptors, cell growth and differentiation. Biochim Biophys Acta 1830, 3908-3916 (2013).

32. Kawa, M. P., Grymula, K., Paczkowska, E., Baskiewicz-Masiuk, M., Dabkowska, E., Koziolek, M., Tarnowski, M., Kłos, P., Dziedziejko, V., Kucia, M., Syrenicz, A., Machalinski, B.: Clinical relevance of thyroid dysfunction in human haematopoiesis: biochemical and molecular studies. Eur J Endocrinol 162, 295-305 (2010).

33. Herold, M. J., McPherson, K. G., Reichardt, H. M.: Glucocorticoids in T cell apoptosis and function. Cell Mol Life Sci 63, 60-72 (2006).

34. Kyrou, I, Tsigos, C.: Stress hormones: Physiological stress and regulation of metabolism. Curr Opin Pharmacol 9, 787-793 (2009).

35. Qiao, S., Okret, S., Jondal, M.: Thymocyte-synthesized glucocorticoids play a role in thymocyte homeostasis and are down-regulated by adrenocorticotropic hormone. Endocrinology 150, 4163-4169 (2009).

36. Talabér, G., Jondal, M., Okret, S.: Extra-adrenal glucocorticoid synthesis: Immune regulation and aspects on local organ homeostasis. Mol Cell Endocrinol 380, 89-98 (2013).

37. Ichii, M., Oritani, K., Kanakura, Y.: Early B lymphocyte development. Similarities and differences in human and mouse. World J Stem Cells 26, 421-431 (2014).

38. Stall, A. M., Wells, S., Lam, K.-P.: B-1 cells: Unique origins and function. Semin Immunol 8, 45-59 (1996).

39. Sen, G., Bikah, G., Venkatamaran, C., Bondada, S.: Negative regulation of antigen receptor-mediated signalling by constitutive association of CD5 with the SHP-1 protein tyrosine phosphatase in B-1 B cells. Eur J Immunol 29, 3319-28 (1999).

40. Pers, J. O., Jamin, C., Le Corre, R., Lydyard, P. M., Youinou, P.: Ligation of CD5 on resting $\mathrm{B}$ cells, but not on resting $\mathrm{T}$ cells, results in apoptosis. Eur $\mathrm{J}$ Immunol 28, 4170-4176 (1998).

41. Gagro, A., McCloskey, N., Challa, A., Holder, M., Grafton, G., Pound, J. D, Gordon, J.: $\mathrm{CD} 5$-positive and CD5-negative human B cells converge to an indistinguishable population on signalling through B-cell receptors and CD40. Immunology 101, 201-209 (2000). 